\title{
Grasberg Block Cave mine: cave planning and undercut sequencing
}

\author{
D Beard Freeport-McMoRan Inc., USA \\ C Brannon Freeport-McMoRan Inc., USA
}

\begin{abstract}
Construction and development of the Grasberg Block Cave (GBC) mine continues to progress, with undercutting commencing in late 2018. As an experienced operator of block cave mines, PT Freeport Indonesia (PTFI) works to improve the planning and execution of undercutting. The GBC mine, with its large size and complex geotechnical conditions, requires increased focus on initiating and sustaining caving.

For the past two years, PTFI has worked on developing a software tool for detailed undercut planning. The tool utilises cave management rules, the geologic block model, and ring shapes to produce detailed tonnage and grade schedules. Additionally, further analytical processing of the tool's output data allows examination of the feasibility and required resources to implement the undercutting plan. As a constraint-based scheduling application, the tool provides a high degree of flexibility in adapting quickly to changing assumptions.

Factors affecting GBC undercutting include high tonnage rates, mine development resources, and variable rock mass conditions. Of primary concern, with production targets between 130,000 and 160,000 tpd, drawbells must open at a sufficient pace to achieve acceptable caving production ramp-up and then maintain throughput targets. Detailed undercut scheduling alleviates those concerns by optimising production block start dates, caving rules, and ring designs, to drive cave production with an achievable drawbelling rate. These detailed schedules also enable vetting of mine development plans, construction plans, and resource requirements.

The GBC geotechnical environment requires undercutting strategies to adapt accordingly. Poor rock mass conditions, large panel boundaries, and high-stress conditions all affect undercut start points, caving directions, and other design decisions. The ability to produce realistic, detailed schedules enables further study of the impacts with 3D numerical modelling. Results from numerical modelling have helped refine not only the caving strategy, but also the overall mine design.

The importance of the undercutting plan for successful caving of the large footprint, high tonnage rate GBC mine remains a priority. In conjunction with the geotechnical engineers and operations personnel, the mine planning team utilises the newly developed undercut planning tool to adapt and improve undercutting plans as more informed data becomes available. The geotechnical and operational challenges to mining the GBC necessitate the methods and approach to planning discussed in this paper.
\end{abstract}

Keywords: undercutting, scheduling, caving

\section{Introduction}

This paper describes the setup and function of an undercut planning tool that generates caving sequences at the level of detail of the individual ring blasts on the undercut level. This tool also generates the drawbell opening schedules that are tied to the undercut advance and are based on the caving rules applied. The scope of the discussion is limited to the undercutting and drawbelling planning and does not extend into the cave production aspects such as draw rates and other cave management topics.

PT Freeport Indonesia (PTFI) began the development of the Grasberg Block Cave (GBC) mine with initial access drifting in 2004, 14 years before the planned initiation of caving in 2018, and almost 20 years prior to achieving full production rates of 160,000 tpd of ore by 2024 (Brannon et al. 2016). 
Since the start of development, PTFI has encountered a series of challenges related to the large footprint size and complex geotechnical conditions of the GBC mine. Updates to the knowledge base of the geotechnical conditions of the orebody continue, including modelling of the mining sequences and influence of those sequences on the stress conditions in the cave. As new results become available, efforts continue on optimising the undercut design and sequence to react to these results. Historically, long-term cave planning at PTFI operations focused on an assumed drawbell opening rate, with the planned undercut sequence a derivative of the drawbelling rate. As PTFI caving operations increased in size over the years, specifically with the Deep Mill Level Zone (DMLZ) mine and the GBC mine, the need for a more accurate approach to planning and scheduling the undercut became apparent.

In conjunction with GEOVIA's Caving Business Unit, PTFI initiated work in 2015 to develop a new planning tool specifically for designing the cave advance, sequencing, and ring blast schedules on the undercut level. Utilising this new tool, PTFI shifted the focus of long-term cave planning from drawbelling rates to undercut ring sequencing, which in turn drives the drawbelling rates. The undercut planning tool now allows users to generate and analyse ring sequences quickly and efficiently.

As PTFI's ability to plan and schedule the undercut improves, so does the ability to mitigate risk from production and geotechnical challenges. By having the capability to quickly and efficiently examine multiple undercut ring sequences, the planning engineers can more fully understand the consequences of design changes. Changes to caving rules can have a wide array of impacts on cave performance and metal production, as well as development and construction schedules and costs. With the undercut planning tool, undercut ring sequences, that are both defendable and practical, function as additional inputs to the ongoing optimisation of the GBC mine plan.

\section{$2 \quad$ Past cave planning practices}

Past PTFI practices for long-term cave planning relied on an assumed drawbelling rate based on the benchmark data from existing caving operations in the district. Short-term planners would then schedule the undercut by hand to match the dictated drawbelling rate. Continuing these practices for $\mathrm{GBC}$, with over 22,000 undercut rings, would prove difficult and time-consuming. The downside to the drawbelling rate planning practice became apparent, as follows.

- Estimation of tonnes and grade: accurate forecasting of production in the early years was not possible as no method existed to separate undercut tonnes and grade from drawpoint production. For GBC, where early-years' undercut production is a significant proportion of total production, the impact on metal production forecasts may not be negligible.

- Adherence to cave management rules: standard practice at PTFI operations features the use of a cave management plan (CMP), which, amongst other functions, identifies and defines rules to govern the undercutting process. With the large footprint and high undercutting rates, maintaining compliance to the CMP, while achieving the drawbelling rate, proved problematic when the drawbelling schedule was driving the undercutting plan.

- Input to numerical models: with the geotechnical challenges at GBC, PTFI uses numeric modelling of the cave propagation to help identify and mitigate risks, such as cave propagation, damage to infrastructure, safety of operators, and seismic response. Simple drawbelling rate scheduling does not provide a satisfactory level of detail for these numerical models, as can be provided with a detailed undercut ring blast sequence.

- Flexibility to change and modify sequences: the large number of rings for GBC presents a computational challenge for scheduling and grade estimation using the drawbelling rate planning practice. When changes or adjustments are required, timing may not always allow for updating the undercut ring sequence.

With these downsides to the drawbelling rate planning practice, PTFI initiated a path forward to develop methods to produce detailed undercutting schedules and drawbelling sequences more efficiently. 


\section{The Tactical Sequencer tool}

Block cave production planning requires modelling the flow of material through drawpoints for estimating the tonnes and grade of the material produced. PTFI uses GEOVIA PCBC ${ }^{T M}$ software (Dassault Systèmes Americas Corp. 2018) for both short-term and long-term drawpoint production planning. When the need for detailed ring sequencing specific to block caving mines arose, a partnership between Freeport-McMoRan Inc. and GEOVIA resulted in an undercut planning tool, known as the Tactical Sequencer (TTL). The TTL tool models, sequences, depletes, and reports the production from each undercut ring for improved undercut planning.

The undercut sequencing process within the TTL tool begins by modelling each undercut ring as a 3D solid and assigning tonnes and grade values from a block model to that solid. Next, the user defines the basic inputs governing the sequencing process. Those inputs include:

- Initiation dates of each production block.

- Undercut tunnel availability dates.

- Undercut tunnel azimuths.

- Cave front shapes and angles.

- Minimum and maximum allowable undercutting rates in metres per day per tunnel.

- Maximum allowable undercut tonnes per period.

Further customisation of the sequencing process requires setting up constraints. Constraints can include undercutting rates (total area undercut per period, undercut area per tunnel per period) and tonnage targets. Correct setup of the sequencing tool allows for accurate representation of all caving rules and guidelines associated with the cave.

The TTL tool sequences and schedules the rings while maintaining adherence to the inputs and constraints defined within the tool setup. Then, the tool schedules the opening of drawbells based on a user-defined distance for the undercut face relative to the drawbell. The result is a ring schedule, a raw unsmoothed drawbell opening schedule, a ring tonnes depletion file for use with PCBC, and the supporting data.

\section{$4 \quad$ Undercutting constraints and inputs}

In addition to improved planning and scheduling, a primary benefit to having a ring sequencing tool is the ability to examine the impact due to adjusted constraints and inputs. Inputs derived from the CMP drive the ring sequencing process.

The CMP presents guidelines, key caving rules, and targets to be applied to the various stages of cave development and for a particular production block. The CMP is an official PTFI document that is reviewed and approved by an internal steering committee that is setup to oversee the management of the caving operations (Villa et al. 2017).

Within the CMP, the key rules that apply to the ring sequencing include undercutting rates (both distance per tunnel per month and total area undercut per month) and the lead-lag for the cave face angle. Additional constraints include available undercut resources that may limit undercutting rates below the CMP rates and ring blasting start dates due to development progress.

Outside of operational constraints, geotechnical constraints may also arise. Ground conditions, rock types, and stress conditions all influence sequencing. Orientation of other infrastructure, relative to the cave fronts, such as the rail haulage level or extraction level, also influence cave initiation points and caving directions.

The TTL tool enables consideration of multiple inputs and constraints to analyse various undercutting scenarios. Since the setup remains consistent across runs and the performance of the software is relatively quick, thorough evaluation of multiple sequences is possible. The size of the footprint and number of constraints do not overly impede the processing time. 


\section{$5 \quad$ Undercut initiation points and cave directions}

For caves, the initiation point and subsequent caving directions are key drivers for the life-of-mine production. Where caving initiates, in which direction it proceeds, and the geometry of the advancing cave face can have a significant impact on metal delivery, ramp-up rates, cave propagation, abutment stress impacts, and other performance characteristics. The TTL tool, by allowing quick creation of detailed ring schedules, enabled a thorough review of the end-2016 production sequence plan. The review highlighted concerns with the sequence, and further use of the TTL tool generated revised sequences to quantify differences for different cave initiation points and caving directions. The changes, discussed further in this section, improved the production sequence for the end-2017 reserves process.

\subsection{End-2016 production sequence}

The GBC footprint features two mining areas on either side of the barren central Kali diorite. The northeastern section, production block PB1, contains three sub-blocks (PB1S, PB1E, and PB1N). The southwestern portion consists of production blocks PB2 through PB4, each divided into three sub-blocks ( $C, N$, and S), and production block PB5. As of the end-2016 reserves statement, caving initiates in the central parts of PB1 and PB2, and caves outward to maximise metal production as shown in Figure 1.

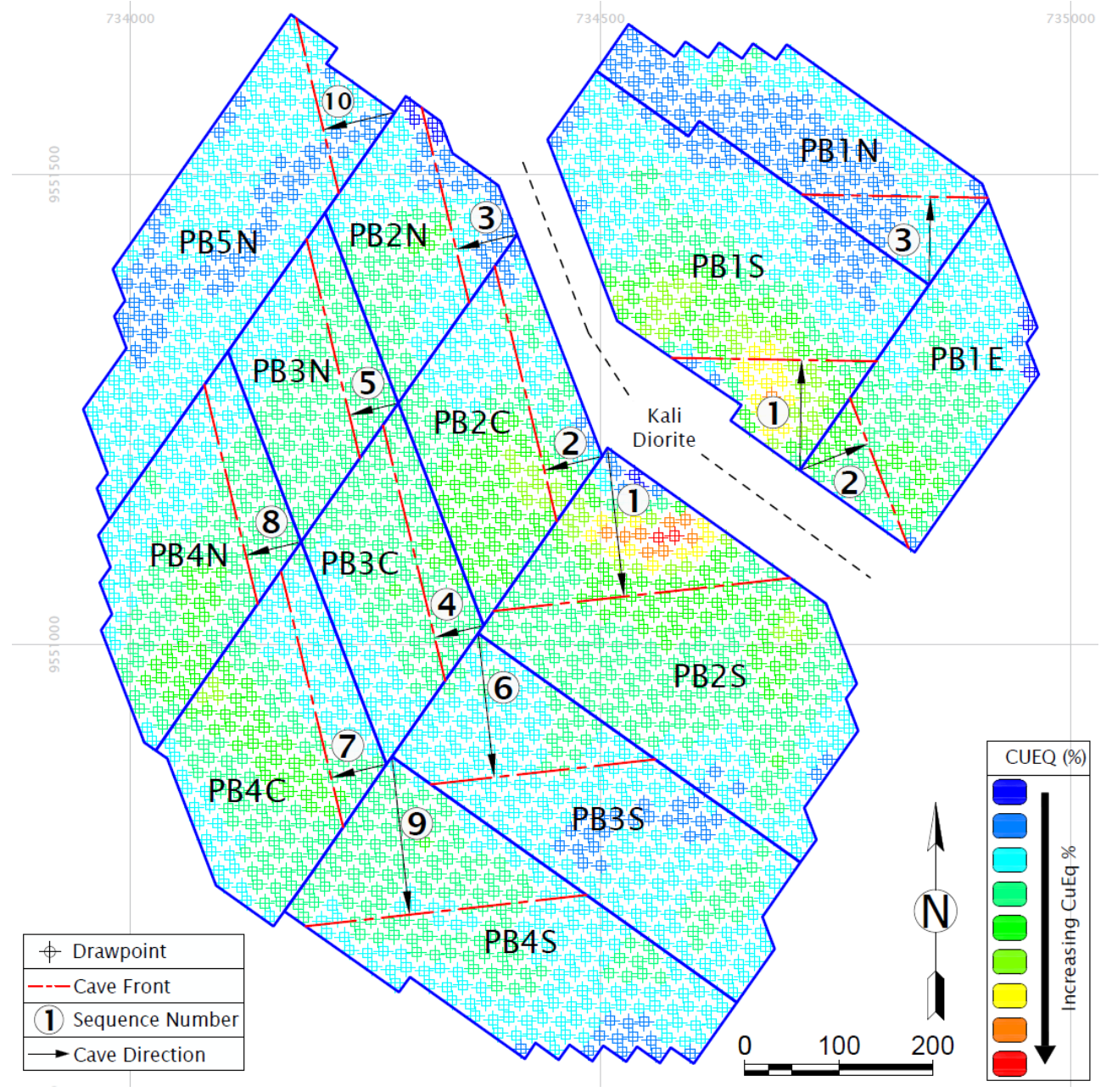

Figure 1 GBC end-2016 reserves footprint and sequence

Since 2016, further study and new information has altered the rationale of the GBC caving plan. Development of a new approach to planning the GBC cave utilised the TTL tool to help assist with the analysis of sequence options. 


\subsection{Production sub-blocks PB1N and PB1S boundary revisions}

Throughout 2016 and 2017, mine development progressed in the PB1 block and identified extensive areas of poor rock mass conditions (termed the Soft Zone), affecting both the undercut and extraction levels. The Soft Zone would require significant additional support with increased development durations - potentially delaying the start of production, and impacting the advance of the cave in PB1. To mitigate this, a revised production plan was developed, which delayed entry into the PB1 Soft Zone at the planned start of production.

To examine potential options, a detailed ring sequence was developed that helped verify the feasibility of the options and provided the initial inputs for further development scheduling and geotechnical analysis. The TTL tool allowed quick generation of ring sequences adhering to the caving rules. Figure 2 shows the resulting end-2017 caving sequence for PB1.

By adjusting the production block boundaries to delay caving the bulk of the Soft Zone, and changing the initial caving direction, the production start date and ramp-up rates remained unchanged from the previous plan. Production advances away from the Soft Zone, which should provide a more reliable cave front as the abutment stress advances away from the Soft Zone. Modelling indicated the chevron approach in the PB1N block would behave superior to a straight caving face moving north across the block at an approximately $45^{\circ}$ angle to the drill drives. The difficulty with the straight cave was in part because the undercut advance would be attempting to maintain the same advance rate in the central Soft Zone as the better ground conditions on either side of the Soft Zone.

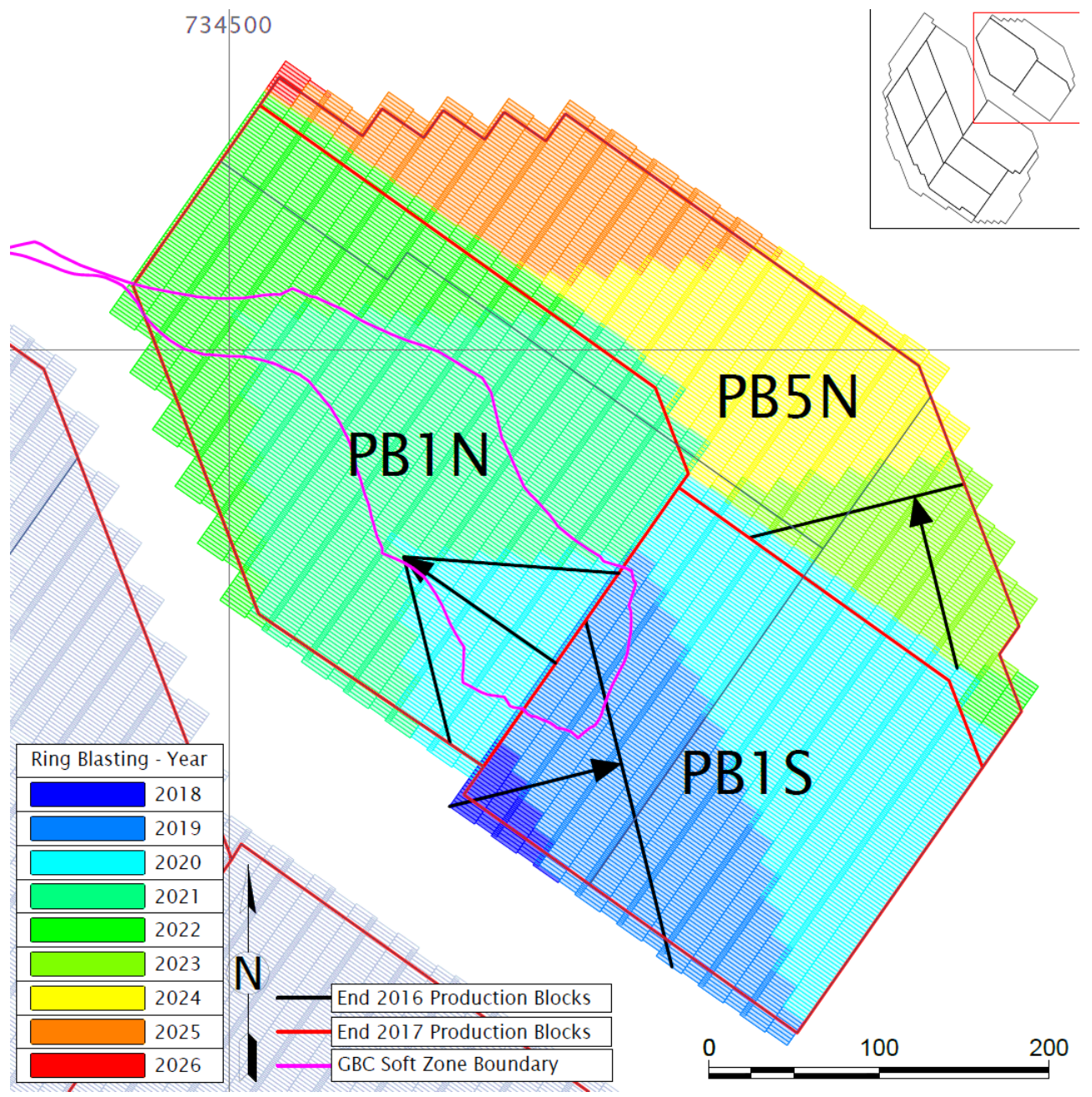

Figure 2 GBC Soft Zone revised production block PB1 boundaries 


\subsection{Production sub-block PB2N sequence revision}

Another issue with the 2016 production plan was the caving direction of the central and northern blocks for production blocks PB2, PB3, and PB4. In those blocks, the end-2016 cave front is parallel to both the block boundary and the main rail track on the haulage level. This alignment of the cave front, boundary, and main rail lines causes two issues. First, because the cave front is parallel, all drill drives (undercut tunnels) must be available for ring blasting at the start date of the block. Second, by having the cave front parallel to the rail line, the abutment stress will pass over the length of the haulage level infrastructure essentially at once, resulting in potentially significant damage to key infrastructure. Figure 3 shows the problematic alignment of the cave front.

As with the PB1 boundary option assessments, the TTL tool allowed testing of many iterations to analyse different sequence options that could mitigate or eliminate the orientation issues. The first step was to combine PB2C and PB2N into one long block (now named PB2N). Then, by switching the initiation point from the northeast to the southeast and adjusting the caving direction, the caving orientation improved (Figure 4).

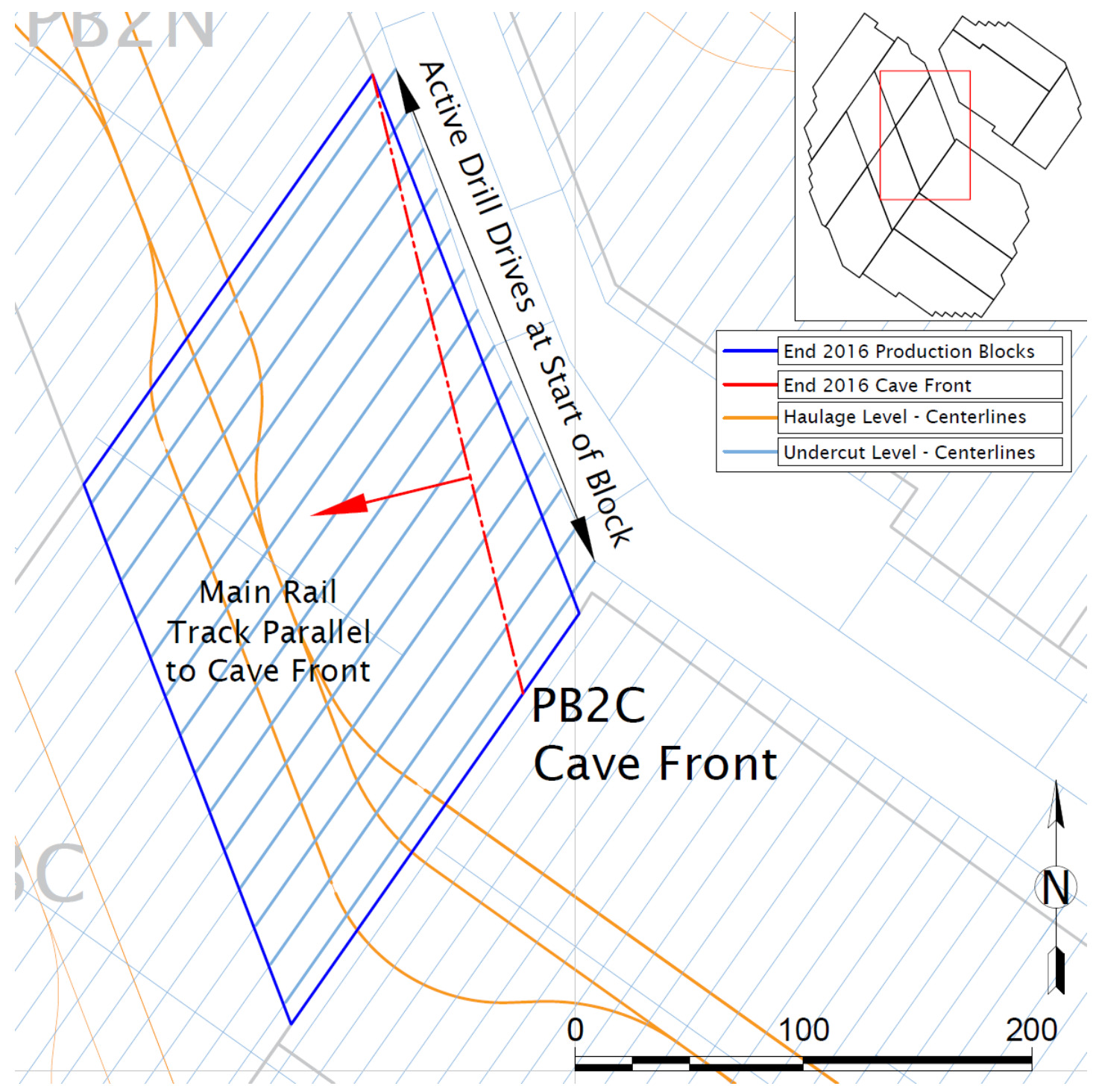

Figure 3 Orientation issues with the end-2016 caving direction 


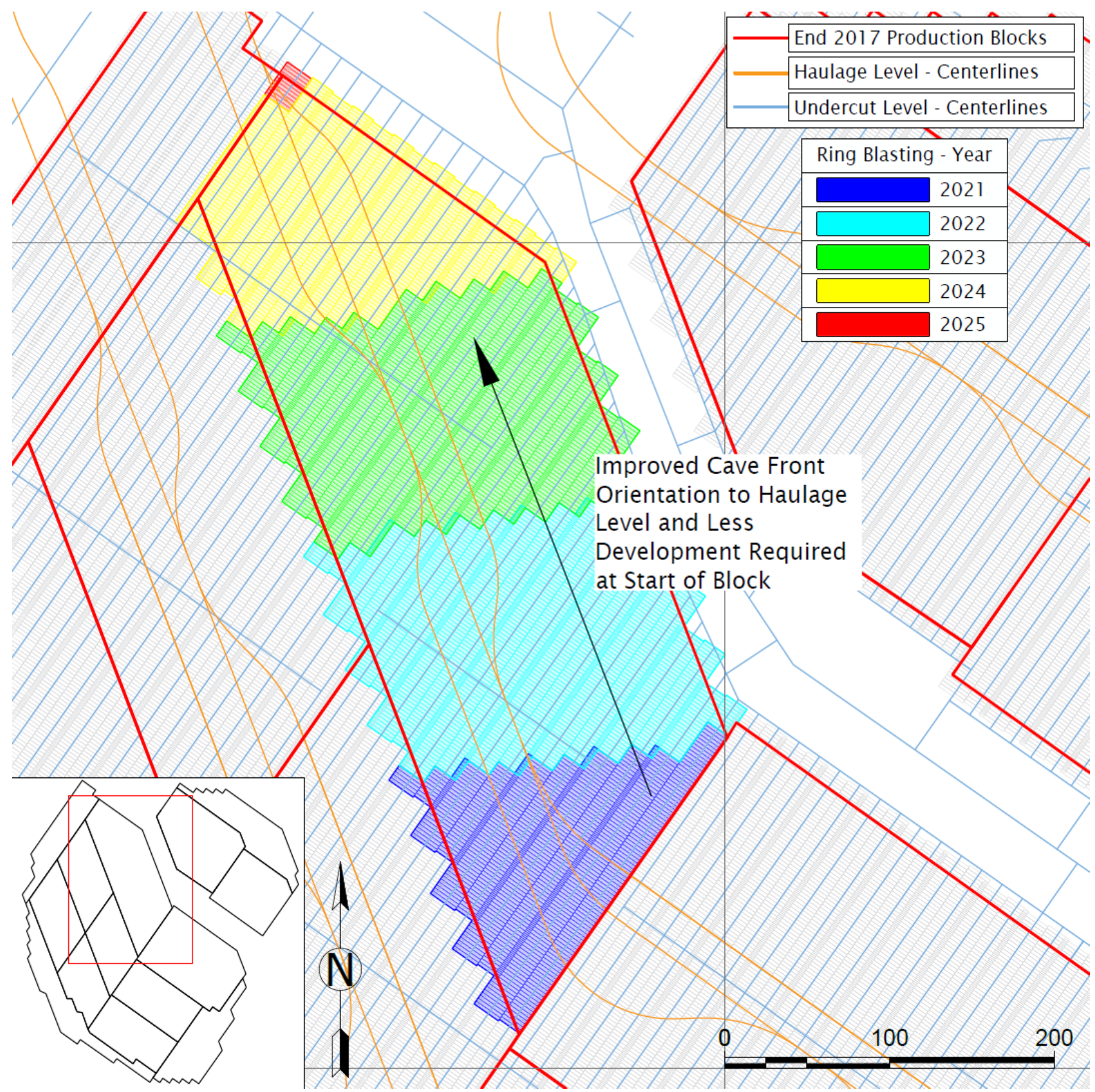

Figure 4 End-2017 caving direction for PB2N

Multiple TTL runs examining various block boundaries and caving directions led to the final end-2017 sequence. Without the TTL tool, it would have been a time-consuming exercise to conduct such an in-depth analysis of the revised caving plan. The revised initiation point and caving direction improved the orientation to infrastructure and decreased the required up-front development to initiate the block.

\section{$6 \quad$ Irregular block boundaries}

One of the more challenging issues with producing a detailed ring schedule includes adhering to the proper lead-lags for the undercut faces and maintaining the cave front angle as specified in the CMP. Irregular production block boundaries and cave stops exacerbate the sequencing complexity. In PB1N for example, rock mass conditions led to the decision to sequence the block along irregular sub-block boundaries.

With the revised end-2017 GBC production plan, PB1N contains the majority of the Soft Zone material. In order to improve the reliability of the cave in this area, the PB1N block utilises a chevron cave front 
following the irregular block boundary resulting from the Soft Zone contact. With this configuration, one undercut face advances in good ground, and the other face advances in poor ground. The point of the chevron roughly follows the Soft Zone contact (Figure 5).

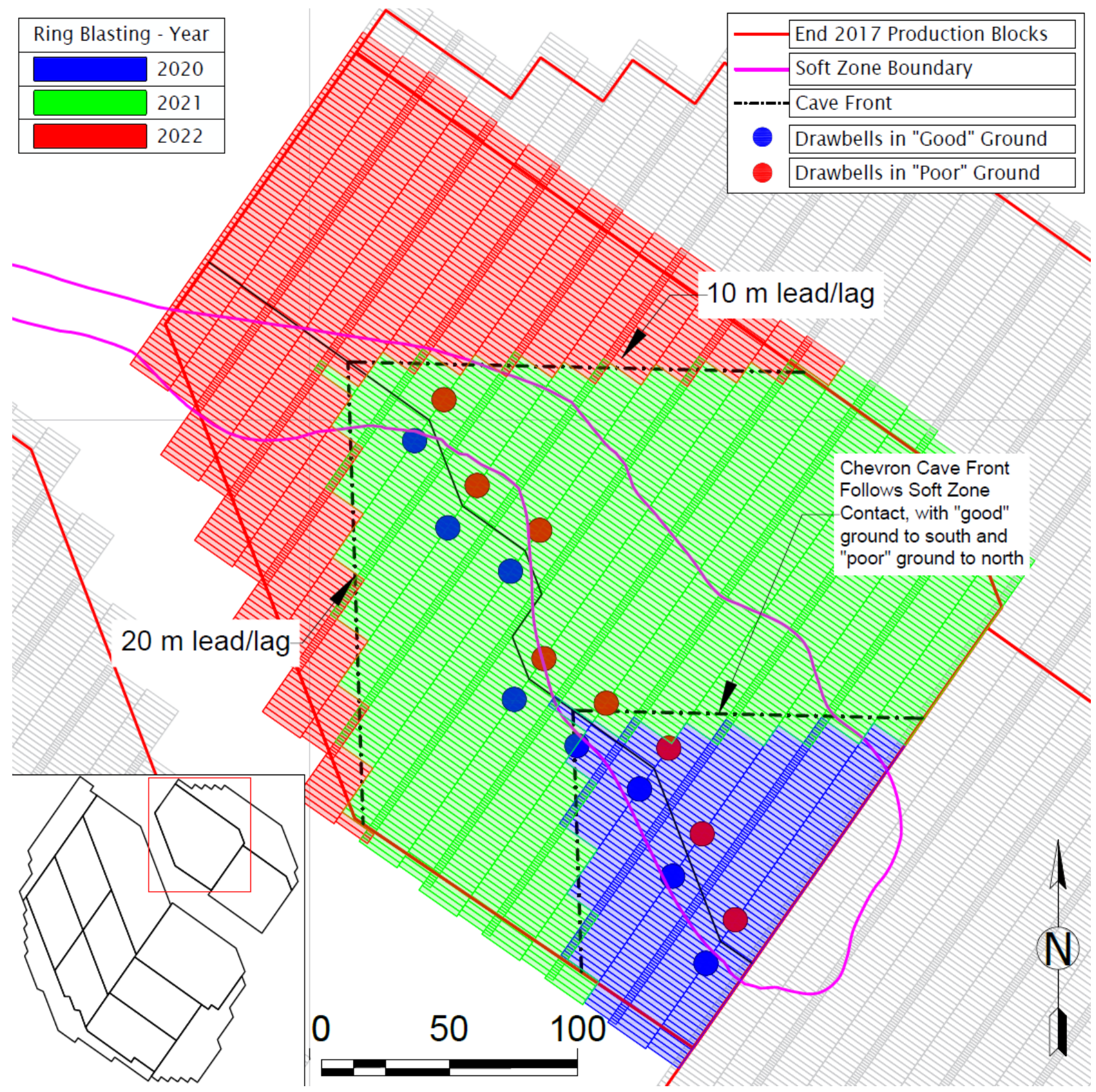

Figure 5 PB1N cave front through the Soft Zone

With the chevron following an irregular boundary, no sequencing solution exists to maintain the same lead-lag on both sides of the boundary. The TTL tool proved effective in analysing constraints on either side of the boundary to generate an acceptable compromise sequence. Even though the revised constraints violated the guidelines in the CMP, further geotechnical review of the sequence, along with input from operations, conferred that it was the best compromise for moving forward with caving in difficult rock mass conditions.

The ring sequence developed for PB1N highlights that, in some instances, a caving sequence satisfying all constraints is not always achievable. The TTL tool allowed for identification of the conflicting constraints, and enabled a compromise solution. Attempting this task by hand, or without a fully capable constraint-based scheduling program, would have proved time-consuming and difficult. 


\section{$7 \quad$ Drawbell opening rates}

A drawbell opening rate derived from the undercut ring sequence and schedule is proving to be one of the more important benefits of using the TTL tool. Past scheduling practices assumed relatively constant drawbelling rates, typically based on benchmarked data from other caving mines in the district, with no tools existing to help validate such assumptions. With complex footprint and production block boundaries, ring sequences continue to show that drawbell opening plans require flexibility to match an achievable undercutting plan. As shown in Figure 6, the TTL tool produces a raw drawbell opening rate representing the number of bells available for blasting per period. This erratic opening rate, as might be expected in a real-life undercutting plan in a multi-block footprint, derives from the user-defined distance governing the distance the undercut face must advance beyond the bell to clear for blasting. This raw opening rate then requires smoothing to produce an acceptable and achievable forecast. The smoothing process can also account for additional constraints on the drawbell opening rate, such as limitations on drawbelling resources.

A consequence of the smoothing process is the accumulation of a 'drawbell inventory'. The inventory represents the number of drawbells per period available but not yet blasted. Tracking the drawbell inventory allows identifying periods where the undercutting sequence may require adjustment. Periods of high drawbell inventory could necessitate delaying production block start dates or slower advance rates, and vice versa for periods of low drawbell inventory.

\section{Drawbell Opening Rate}

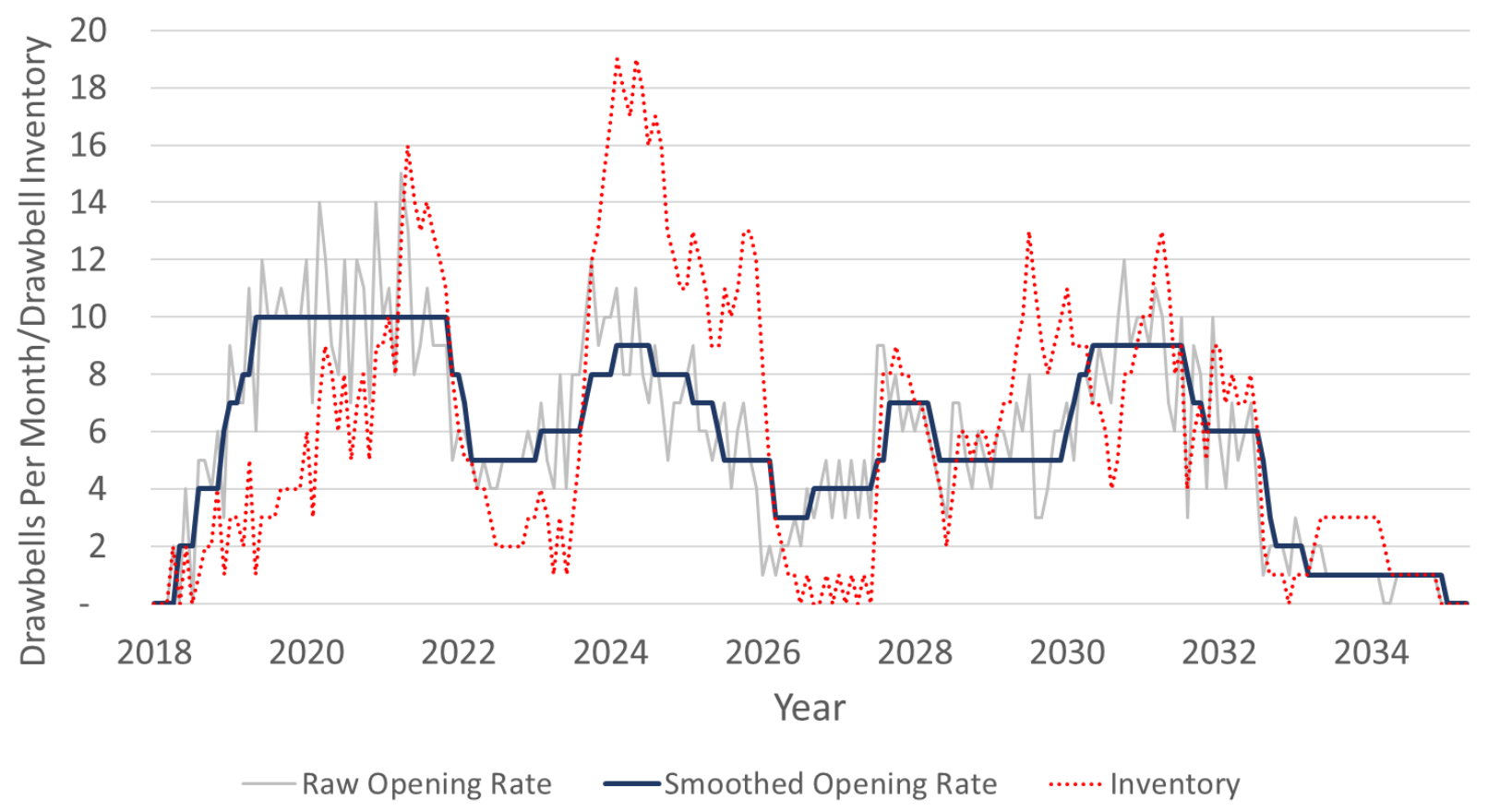

Figure 6 Drawbell opening rate

\section{Current overall sequence}

Work continues on modifying and optimising the production block boundaries, initiation points, and caving directions. The planning issues described in this paper also apply to the other production blocks in the overall footprint. Successful caving of the GBC mine will require continual optimisation of the caving parameters. Figure 7 shows the current state of the proposed GBC undercutting plan as of Q2 2018. The sub-blocks in production blocks PB3 and PB4 are combined into a single block to allow for a more favourable cave front orientation. The planning for GBC undercutting and production will continue to evolve in part because the tools now exist to examine options in detail and to enable adjustment of the plans efficiently. 


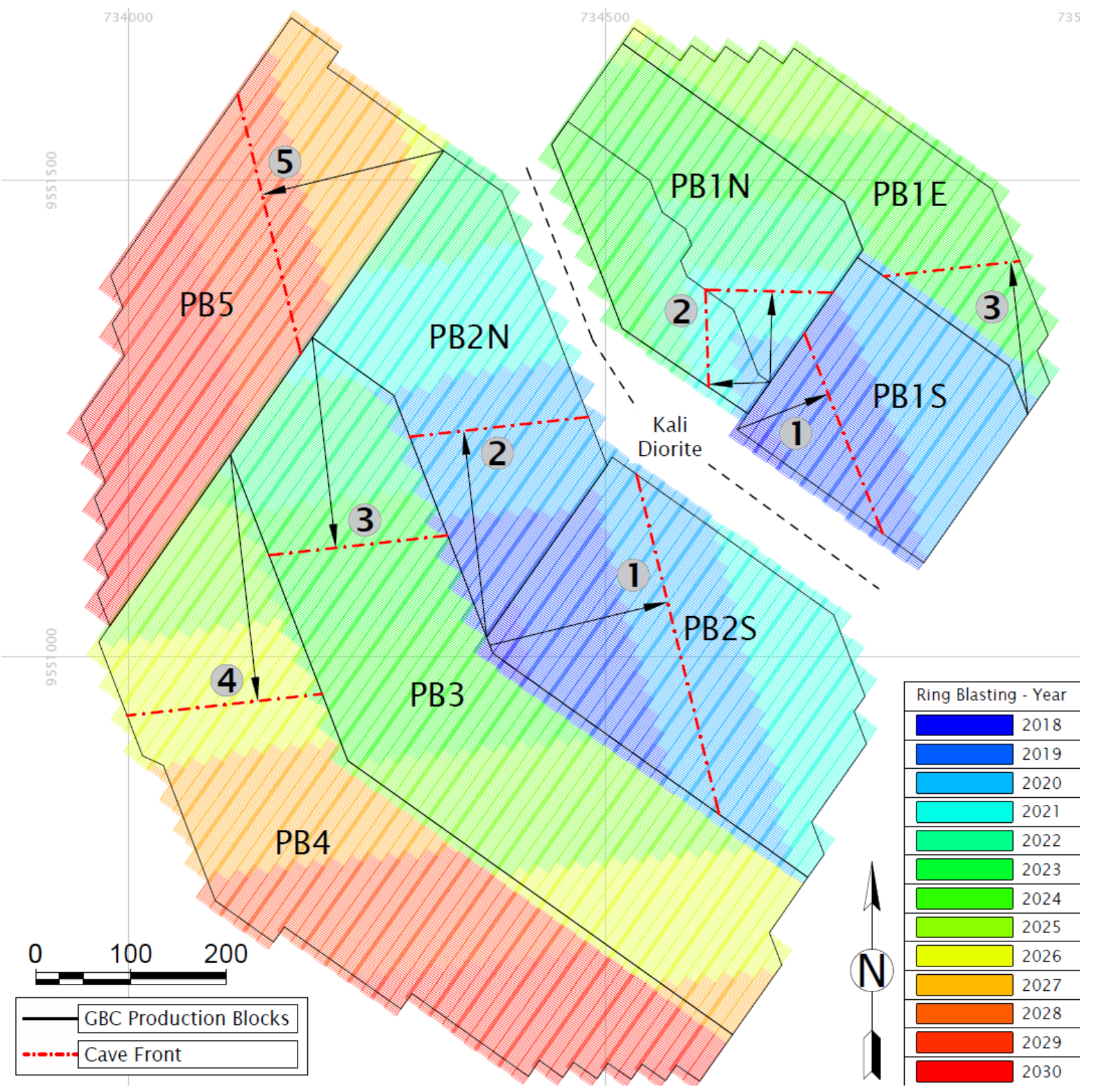

Figure 7 Current overall GBC undercutting sequence

\section{$9 \quad$ Geotechnical modelling inputs}

The TTL tool produces comprehensive data for all aspects of the forecasted undercut ring sequence. Data from the TTL tool can feed into a 3D finite element stress analysis of the cave behaviour. The results of the stress model helps validate caving plans, influence design recommendations, and support decisions.

Results of the 3D stress modelling improves the cave planning process, creating a loop for continual improvement of the designs. Some of the issues that the modelling can highlight include:

- Impact of caving directions on other mine development and infrastructure.

- Impact of caving directions on pillars and production block boundaries.

- Cave propagation and caving behaviour.

Without the detailed ring sequences, numerical modelling results may not accurately reflect the caving plan. 


\section{Conclusion}

The Grasberg Block Cave mine is nearing initiation of caving activities, transitioning from pre-production planning to cave management. As mine development and construction progresses, efforts continue to review and optimise the planned caving sequence in preparation for the start of production. The methods and tools outlined in this paper provide an overview of the detailed approach adopted by PTFI for undercut scheduling and sequencing. These methods and tools enable efficient creation of detailed ring blast sequences. Modelling the undercut ring blasting on a ring-by-ring basis improves the reliability of the production plan, and enables the identification and mitigation of potential operational risks. Detailed ring sequencing also produces data for comprehensive geotechnical analyses regarding the performance of the cave front. The ability to conduct detailed long-range undercut planning also contributes to improved short-range cave planning and execution.

The magnitude of the GBC project is almost unprecedented. Once caving is underway, there will undoubtedly be challenges encountered that require modification of the undercutting plans produced on paper. The new undercutting planning tools allow quick reaction to changed conditions, to produce revisions to the plan quickly and efficiently. Work will continue on improvements to the undercutting tools, with the anticipation that these tools become a significant component to the cave management practices at GBC, as well as at the other active caving mines of PT Freeport Indonesia.

\section{Acknowledgement}

Continuous improvement and optimisation of the GBC caving plan requires the hard work and participation of many various entities. The authors of this paper thank the GBC planning and geotechnical teams for their input and assistance. Additionally, the authors thank GEOVIA for their efforts developing the sequencing tool. As GBC moves towards full production, cave planning will require continued support to overcome the challenges of operating a truly world-class block cave mine. The permission of Freeport-McMoRan Inc. to publish this paper is also acknowledged.

\section{References}

Brannon, CA, Firdausi, HH, Pascoe, ND \& Yuniar, AT 2016, 'Development and construction update of the Grasberg Block Cave mine', Proceedings of MassMin 2016, The Australasian Institute of Mining and Metallurgy, Melbourne.

Dassault Systèmes Americas Corp. 2018, PCBC, computer software, Dassault Systèmes Americas Corp., Waltham, https://www.3ds.com /products-services/geovia/products/pcbc/

Villa, D, Brannon, CA, Dipas, CA \& Vega, HA 2017, 'Integrated drawbell and undercut scheduling using a computational tool at the Grasberg Block Cave mine', Proceedings of the 13th AusIMM Underground Operators' Conference 2017, The Australasian Institute of Mining and Metallurgy, Melbourne. 
